\section{Effect of "Understand and Solve!" Strategy Instruction on Mathematical Problem Solving of Students with Mild Intellectual Disabilities}

\author{
Alpaslan Karabuluta, ${ }^{\text {}}$, Emine Rüya Özmen ${ }^{b}$
}

$\begin{array}{ll}\text { Received: } & 14 \text { September } 2018 \\ \text { Revised: } & 10 \text { November } 2018 \\ \text { Accepted: } & 16 \text { November } 2018 \\ \text { ISSN: } 1307-9298 \\ \text { Copyright @ IEJEE } \\ \text { www.iejee.com }\end{array}$

DOI: 10.26822/iejee.2018245314

\begin{abstract}
The purpose of this study was to examine the effects of "Understand and Solve!" Strategy on change problems including change of a one-step addition and subtraction of children with mild intellectual disabilities and whether they maintained their achievements 3, 5, and 8 weeks after the intervention. Moreover, the effects of the Understand and Solve! Strategy on generalization to different types of problems and multiple step problems as well as on the perception, attitudes, knowledge, use, and control of problem solving strategy were investigated. Three students with intellectual disabilities who were 11 to 12 years old and attended 5th grade participated in the study. "A Multiple Probe Design Across Subjects," which is one of the single subject research designs, was used in the study. The findings of this study showed that Understand and Solve! Strategy was effective in teaching students with mild intellectual disabilities solving change problems including one-step addition and subtraction, they maintained their skills and generalized their skills to different problem types, two-step change problems. As a result of the intervention, students' perception and attitudes towards mathematics as well as knowledge, use and control of strategies to solve mathematical problems positively changed.
\end{abstract}

Keywords: Cognitive Strategy Instruction, Self-Regulation Strategies, Problem Solving, Mild Intellecutal Disabilities

\section{Introduction}

Problem solving, which is one of the principal achievements during elementary school years, constitutes an important place in every stage of life during both school years and after. Problem solving is a comprehensive process in itself while it consists of calculation, prediction, and thinking (The National Council of Teachers of Mathematics [NCTM], 2000). Solving a mathematical problem is defined as a complex cognitive activity which involves several processes and strategies (Montague, 2000). During this activity, cognitive and metacognitive processes and strategies are used (Montague, 2008; Montague \& Dietz, 2009; Özsoy \& Ataman, 2009). Cognitive processes used in problem solving are comprehension, translating, transforming, planning, predicting, calculating, and evaluation (Montague, 1992). However, cognitive strategies include strategies beginning from reading the problem to controlling the process such as a) reading, b) describing in own words, c) predicting, d) visualizing the problem on a paper or visualizing it by mental imaging, e) developing hypotheses, f) calculating, and g) controlling (Montague, 1992; Montague \& Bos, 1986). Metacognitive processes focus on the awareness of the cognitive knowledge that manages and organizes the cognitive processes that are needed for problem solving. This awareness includes strategy knowledge and use and strategy control (Montague, 1992). The metacognitive strategies i.e., self-regulation that provides for strategy organization and awareness used in problem solving involve self-instruction, self-question, and self-monitoring (Montague, 1992; 2007; 2008).

Students with mild intellectual disabilities have issues in the achievement of the problem solving skills which constitute a challenging and complex process (Geary, 1994; Özsoy, Kuruyer \& Çakıroğlu, 2015). Most of these students have problems in identifying important information in the problem and transforming verbal and numerical information into operations (Montague, 1997). In addition, students with mild intellectual disabilities usually have limitations in the use of cognitive and metacognitive strategies (Geary, Brown, \& Samaranayake, 1991). Therefore, while teaching these students how to solve mathematical problems, not only procedural steps but also the necessary cognitive and metacognitive strategies to follow these steps are also taught.

The primary approaches that try to teach problem solving by instructing problem solving strategies to children are process based approaches. In process based approaches, in general, the teacher models the process to the student by thinking aloud the steps in order to teach the necessary cognitive and metacognitive strategy use during the problem solving process (Montague, 2008). The purpose with it is to have the students internalize the strategy by allowing interactional dialogs and procedural facilatators (Güzel-Özmen, 2006).

The Cognitive Strategy Instruction, which contains the elements of cognitive and metacognitive strategy teaching in mathematical problem solving and is a process based approach, was used with both students with learning disabilities (Cassel \& Reid, 1996; Daniel, 2003; Iseman \& Naglieri, 2011; Krawec et al., 2012; Krawec, 2014 ; Maccini \& Gagnon, 2001; Maccini \& Hugles, 2000; Mancl, 2011; Montague \& Bos 1986; Montague \& Dietz, 2009; Montague, 1992; Montague, 2008; Montague et al., 2011; Naglieri \& Das, 1997; Naglieri \& Gottling, 1995; Naglieri \& Johnson, 2000; Rosenzweig, Krawec, \& Montague, 2011; Swanson, Orosco, \& Lussier, 2014) and mild intellectual disabilities (Chung \& Tam, 2005; Cote, Pierce, Higgins, Miller, Tandy, \& Sparks, 2010; Huffman, Fletcher, Grupe, \& Bray, 2004; Keogh, Whitman, \& Maxwell, 1988; Van Luit \& Van der Aalsvoort, 1985); and it was found to be effective. Montague and Dietz (2009) evaluated the studies which tested the effectiveness of cognitive strategy instruction in solving mathematical problems. The analysis showed that cognitive strategy instruction could not be defined as an

\footnotetext{
a, ${ }^{*}$ Corresponding Author: Alpaslan Karabulut, Abant Izzet Baysal University, Faculty of Education, Department of Special Education, Bolu/Turkey. E- mail: alpaslankarabulut@hotmail.com, Phone: +905052999914

Gazi Üniversity, Gazi Faculty of Education, Department of Special Education, Bosna-Hersek Block, Z-12, Teknikokullar, Ankara, Turkey. E-mail: ruyaozmen@hotmail.com
} 
evidence-based practice in teaching solving mathematical problems. Authors suggested that there is a need for more experimental evidence. This result shows that the number of research studies in which criteria of evidence-based practices are implemented must be increased. Some studies have been conducted since 2009 that show that cognitive strategy instruction was effective for students with intellectual disabilities and learning disabilities (Cote et al., 2010; Krawec et al., 2012; Krawec, 2014; Montague, Enders, \& Dietz, 2011; Swanson et al., 2014; Swanson, Lussier, \& Orosco, 2013). A Cognitive Strategy Instruction Model namely "Solve It! Strategy," which involves cognitive and metacognitive elements, was developed Montague (1992) and it is one of the process based teaching strategies. Solve It! is a strategy which aims to teach seven cognitive strategy steps (i.e., read, paraphrase, visualize, hypothesize, predict, calculate, and check) and in each of the cognitive strategy step it contains three metacognitive steps (ask, say, and check). This strategy was used to teach solving word problems to middle school students with learning disabilities (Daniel, 2003; Krawec, Huang, Montague, Kressler, \& Alba, 2012; Montague,1992), Spina Bifida (Mesler, 2004), and it was found to be effective. Chung and Tam (2005) also found that Solve It! Strategy, of which strategy steps were modified, was effective in teaching mathematical problem solving skills to middle school students with mild intellectual disabilities.

Another process based approach in problem solving is the Self-Regulated Strategy Development (SRSD) (Case, Harris, \& Graham, 1992). The process aims to develop metacognitive strategies that are needed to solve the problems. This approach targets teaching some self-regulation strategies (such as self-instruction, self-monitoring, self-reinforcement) and students are expected to self-regulate during the problem solving process. SRSD teaching which aims to teach strategy steps and self-regulation strategies used in problem solving includes a) developing and activating background knowledge, b) discussing the strategy, c) modeling of the strategy, d) memorizing the strategy, e) supporting the strategy, and f) independent performance. In order for the students to move from one stage to another the student has to meet the criteria for remembering and implementing the strategy. Therefore, SRSD is a criterion-based implementation (Case et al., 1992). Case et al. (1992), accelerated the process of student's learning the strategies and independent use of these strategies in solving mathematical problems by modifying Self Regulated Strategy Development approach.

A review of the studies conducted in the literature showed that there is only one study which aimed to teach students with intellectual disabilities solving mathematical problems in Turkey (Karabulut, Yıkmış, Özak, \& Karabulut, 2015). In that study the effects of schema-based instruction on the mathematical word-problem-solving performance of students with intellectual disabilities were examined. Since students with intellectual disabilities have problems in using cognitive strategies (Chung \& Tam, 2005) and self-regulation (Cassel \& Reid, 1996) during solving mathematical problems, and thus they utilize explicit and sequence step presentation, there is also a need to test the effects of multi-element cognitive strategy teaching modified for the characteristics of students with intellectual disabilities.

Therefore, the purpose of this study was to examine the effects of Understand and Solve! Strategy, which was designed to utilize Modified Solve It! Strategy and in clude self-regulation strategies such as self-instruction and self-monitoring during the strategy steps, on solving change problems including a one-step addition and subtraction for students with mild intellectual disabilities.

\section{Method}

\section{Subjects}

Three students with mild intellectual disabilities who were first graders of special education classrooms in middle schools participated in this study. The inclusion criteria for the subjects were that a) they had $80 \%$ accuracy in additions with involving regrouping in addition and subtraction (Case et al., 1992), b) the rate of accuracy was at least two, at most four, out of 10 operations including change of a one-step addition and subtraction. Out of five students who met these criteria three were randomly chosen as study subjects.

The first student was 12 years and 3 months old girl who was a middle school first grader with 70 IQ score and mild intellectual disability. She was able to accurately solve nine out of 10 additions with regrouping and eight out of 10 subtractions with regrouping. She correctly solved three out of 10 problems including change of a one-step addition and subtraction. She had no additional disabilities.

The second student was 11 years and 9 months old boy who was a middle school first grader with 69 IQ score and mild intellectual disability. He was able to accurately solve 10 out of 10 additions with regrouping and nine out of 10 subtractions with regrouping. He correctly solved four out of 10 problems including change of a one-step addition and subtraction. He had no additional disabilities.

The third subject was 11 years and 8 months old girl who was a middle school first grader with 67 IQ score and mild intellectual disability. She was able to accurately solve nine out of 10 additions with regrouping and nine out of 10 subtractions with regrouping. She correctly solved four out of 10 problems including change of a one-step addition and subtraction. She had no additional disabilities. All three subjects were attending special education classrooms.

\section{Setting}

The study sessions were conducted in a $7 \mathrm{~m} \times 5 \mathrm{~m}$ dimensions, empty classroom which was designed as an art studio. A video recorder was placed in the room to record the sessions for inter observer reliability and procedural fidelity.

\section{Dependent and Independent Variables}

The dependent variables of the study were the number of correctly solved change problems including a one-step addition and subtraction; knowledge, use, and control of mathematical problem solving strategy; attitudes towards mathematics; and attitudes towards solving mathematical problems. The independent variable was Understand and Solve! Strategy.

\section{Research Design}

In this study a multiple probe design across subjects was used to identify the effects of Understand and Solve! Strategy skills of students with mild intellectual disabilities regarding change problem including a one-step addition and subtraction.

While the multiple probe design across subjects was implemented in the study, one probe was conducted with each of the three subjects separately on the same day in order to assess the performance of students regarding change problem solving. With the first subject that the intervention would be initiated, three separate sessions of baseline level data were collected. When the first sub- 
ject's problem solving performance showed consistency, with the first subject Understand and Solve! Strategy was initiated to teach solving problems. As in the baseline, three consecutive probe sessions were conducted following intervention (post-instruction). When the first subject reached the criterion of $90 \%$ or more rate of accuracy with stable data patterns, with the second subject three consecutive sessions were conducted to assess the baseline of the performance related to solving mathematical problems. At the same time, one probe session was conducted with the third subject. The same process was implemented likewise until the independent variable was implemented with all three subjects. In order to assess the sustainability of the skill achievements post-intervention; 3,5 , and 8 weeks following the intervention one time follow-up data were collected with each of the subjects. Moreover, generalization data were gathered in the baseline, post-instruction, and follow-up in order to identify the generalization performance of the subjects on one-step categorization and comparison problems, and two step change problems.

\section{Development of Understand and Solve! Strategy}

The steps of Understand and Solve! Strategy was developed utilizing the Modified Solve It! Strategy. Firstly, cognitive strategy steps of Solve It! were modified. The students are asked to draw a picture or a diagram related to the problem in the "visualize the problem" step, which is one of the steps of Solve It! cognitive strategy steps. However, in this study the students were asked to choose an appropriate schema related to the problem and they were asked to place the problems into the schema. Secondly, self-regulating strategy approach was adopted as the instructional method (Case et al., 1992). All the steps included developing and activating background knowledge, discussing the strategy, modeling of the strategy, memorizing the strategy, supporting the strategy, and independent performance. (Case et al., 1992; Reid \& Lienemann, 2006). In this study, It was aimed that; a) development of all prerequisite skills required from the students in order to use the strategy and b) explicitly helping students to teach them how to use the strategy by using this steps; As a result, students are able to learn all the process which is important in understanding and solving the problems as well as organizing the problem solving process and achieving more general metacognitive strategies regarding evaluation (Case et al., 1992). Thirdly, as a feature of SRSD approach, two of the self-regulation strategies namely self-instruction (identification of the problem, directing attention and planning, strategy, self-assessment and error correction, coping with the issues and self-control, self-reinforcement) and self-monitoring were used. Lastly, procedural facilatators used in the cognitive strategy instruction were included to make the students internalize the self-instruction and teach the strategy (Doğanay-Bilgi, 2009; Englert, Raphael, \& Anderson, 1992; Güzel-Özmen, 2006; Güzel-Özmen, 2011).

\section{Understand and Solve! Strategy Instructional Stages}

For each of the instructional stages of the Understand and Solve! Strategy (Read the problem and tell, underline the keywords, draw the schema of the problem, make a plan and solve the problem, control it), an instructional plan and procedural facilatators were prepared by utilizing the previous sources (Casse et al., 1992; Chung \& Tam, 2005; Montague, 2000; Montague, 1992; Reid \& Lienemann, 2006).

Strategy steps which can be seen in Table 1 are presented in five stages.

Developing and activating background knowledge. In order for the student to implement the Understand and Solve! Strategy keywords (remains, left, decreased, spent, etc.) that could lead the child in solving the problem were taught (Case et al., 1992). Since the performance regarding the operation was set as a prerequisite, during the stage of enacting prior knowledge, operations were not performed. This stage continued until the students learned the keywords which would lead them in the problem solving (Case et al., 1992).

Discussing the Strategy. In this stage, the benefits of using the strategy were explained. The steps of the strategy were introduced, what can be done on each step and which of the procedural facilatators could be utilized were

Table 1. Understand and Solve! Strategy steps

\begin{tabular}{ll}
\hline 1. Read the Problem and Tell! & $\begin{array}{l}\text { The purpose is that the student read the problem and then tell it in her or } \\
\text { his own words to solve it. Sample self-instruction statements are as follows "I } \\
\text { can understand if I read carefully, I will read it once and if I don't understand } \\
\text { I will read again, I can understand the problem better if I look at my problem } \\
\text { worksheet" }\end{array}$ \\
\hline $\begin{array}{l}\text { 2. Underline the Keywords! } \\
\text { determination of the operation by identifying the keywords which constitute } \\
\text { the problem by underlying the words which cause mathematical change } \\
\text { in the problem. Sample self-instruction statements are "I will identify the } \\
\text { important words, I will read the problem carefully and if I don't understand } \\
\text { it I will read it again" }\end{array}$
\end{tabular}

3. Draw the Schema of the Problem! The purpose here is to make the problem be easily understood by visualizing what is known and what is required. Sample self-instruction statements are "I will write all the things I know on the related place of the schema, then I will find what is required of me"

4. Make a Plan and Solve the Problem! The purpose is to identify and write down which operation to be used and what steps to follow in order to reach the desired outcome starting from what is known. Sample self-instruction statements are "this is the most important part, I need to be careful, I know what is asked of me, I will find the necessary operation"

5. Check! The purpose is to control all the steps that the student has gone through starting from reading the problem until calculation. Sample self-instruction statements are "I need to control all the steps" 
explained (Milford \& Harrison, 2010; Reid \& Lienemann 2006). The student and the researcher discussed why and how each of the strategy step would be used in one step addition and subtraction problems as well as what we could think as we use the strategy and the importance of what we might think were discussed. While introducing the steps of the strategy, Understand and Solve! Strategy Monitoring Checklist was used. This list consists of two columns. On the first column, the titles of the strategy steps and symbolic pictures to make the strategy steps easily remembered were used; on the second column there is an empty space for the students to check after they complete each step.

Modeling of the Strategy. In this stage, all of the steps of the Understand and Solve! Strategy are implemented by using procedural facilatators and Strategy Monitoring Checklist by thinking aloud. How to implement the strategies of self-regulation which includes self-instruction and self-monitoring are modeled through thinking aloud. In this session, models were presented for four problems. In this study, Memorizing the Strategy, which is one of the instructional stages of the self-regulation approach, was not included, instead in order for the students to make transitions from modeling to guided practice, it was planned that the students repeated the strategy steps, used self-instruction and self-monitoring through all the steps. How and why to use each of the procedural facilatators in each step of the problem solving strategy was modeled through thinking aloud.

During the modeling stage Understand and Solve! Strategy Monitoring Checklist was used to support the student by checking each step s/he completes while solving the problem making her/him able to identify the step s/he is at. In addition, in this stage for Read the Problem! Step, to facilitate understanding of the problem, the Problem Reading Sheet was used. This sheet consisted of three columns. On the first column there are questions to facilitate the understanding of the problem. On the second column there is a space for the student to write her/his answers. On the third one s/he can check the questions that s/he cannot answer.

During the "Draw the schema of the problem to make it easier!" stage, a "Change Problem Schema" was used to facilitate the drawing of the schema related to the problems including change. This schema includes three separate clusters to write down the amount of beginning, change and ending. In the "Plan and solve the problem!" step, a Planning Sheet was used that would facilitate which operation to be used in the problem solving and which steps could be taken in what order. This sheet is a procedural facilatator that was prepared for the student to write down the process prior to problem solving in order. In the "Do the calculation!" step of the strategy a Problem Solving Sheet, which is an empty paper, was used to perform the calculations. Lastly, at the last step of the strategy which is "Check it!" the "I Monitor Myself Checklist" was used to enable the student check whether s/he has implemented necessary strategies for the problem. This list is a procedural facilatator which consists of two columns, one with questions prepared for the student to check the things s/ he has to do at every stage and the other one with space to put a mark.

Supporting the strategy. In this stage, when the student became more experienced and self-confident in using the strategy the procedural facilatators were faded. In each of the guided practice sessions, students were guided through solving four problems. Guided practice continued until the student became independent in using the strategy and used the self-instruction statements correctly in the right place.

Independent Practice. In this stage the students were encouraged to solve the one-step addition and subtraction problems using the strategy independently. In the independent practice stage when the students met the criteria of answering nine out of 10 problems correctly this stage was terminated, and post-intervention assessment was conducted.

\section{Preparation of Target Problems}

In this study four types of problems were used: in the assessment and instructional sessions change problems including a one-step addition and subtraction, in the generalization one-step categorization and comparison problems, and two step change problems. The problems were prepared similar to the problems in the elementary school books included by Ministry of National Education and they consisted of problems including change, categorization, and comparison.

For preparation of the problems a total of 240 one-step change problems ( 80 problems in each of the categories including unknown starting amount, change amount, and outcome amount), 120 one-step categorization problems (60 problems in each of the categories including unknown total amount and unknown amount for a part), 120 onestep comparison problems (40 problems in each of the categories including unknown amount of difference, comparison, objects or concepts), 10 two-step change problems (60 problems in each of the categories including unknown starting amount and outcome amount). Problems were written with 12-point Comic Sans MS characters, 1.5 line spacing on an A4 paper. All the problems prepared were used in the research process. In Table 2 the number and type of problems used in each experimental stage are included.

\section{Data Collection Instruments}

In order to measure the dependent variables of this research Problem Solving Record Chart, Mathematical Prob-

Table 2. The number and type of problems used in each experimental stage

\begin{tabular}{|c|c|c|c|c|c|c|}
\hline Type of Problems & Baseline & $\begin{array}{l}\text { Generalization } \\
\text { to Classroom } \\
\text { Performance } \\
\text { Baseline }\end{array}$ & $\begin{array}{c}\text { Post- } \\
\text { Intervention }\end{array}$ & $\begin{array}{c}\text { Generalization } \\
\text { to Classroom } \\
\text { Performance } \\
\text { Post- } \\
\text { Intervention }\end{array}$ & $\begin{array}{l}\text { Generalization } \\
\text { of Strategy } \\
\text { Performance to } \\
\text { Classroom Post- } \\
\text { Intervention }\end{array}$ & Follow-up \\
\hline One-step change problems & 50 & 10 & 30 & 10 & 10 & 30 \\
\hline One-step categorization problems & 30 & & 10 & & & 30 \\
\hline Two-step change problems & 30 & & 10 & & & 30 \\
\hline
\end{tabular}


lem Solving Assessment Form, Strategy Observation Form, and Social Validity Questionnaire were used. In the following section information related to data collection tools and the data collection process are explained.

Problem Solving Record Chart. In order to determine the number of correctly solved problems, a chart was prepared for recoding the answer of each problem. On top of the chart the personal information and date are written and under that there is a chart to record the answers given to 10 problems. The number of correct answers were calculated by recording the answers of students on this chart.

Strategy observation form. Ten questions were provided to the students in the classroom environment and strategy observation form was used to examine the generalization of the strategies that the students used in solving change problems including one-step addition or subtraction to the classroom environment. In this form cognitive strategies involved in Understand and Solve! Strategy were included. Students were observed in the classroom and whether they used the strategies or not were recorded. In addition, answers of the students were recorded on the Problem Solving Record Chart to identify their correct answers.

Mathematical problem solving assessing short form (MPSA-SF). Mathematical Problem Solving Assessing Short Form (MPSA-SF) was developed by Montague (1992). It is an informal diagnostic instrument to identify the strong and weak sides of the students in solving mathematical problems (Montague, 1992). In the form there is a part that contains information related to the student. The form includes a total of 40 items in two parts. The first part of the form includes 10 questions, five of them are open-ended and other five are 5-point Likert-type statements to identify the students' mathematical perception, attitudes towards mathematics, and attitudes towards problem solving. The second part of the form contains 30 open-ended questions that were prepared to identify the problem solving strategy knowledge, use, and control. For reading strategies, the questions 11-17, for interpretation 18-21, for visualization 22-25, for hypothesis 26-29, for prediction 30-33, for calculation 34-36, for checking 37 39 , and to identify mathematical problem solving strategy knowledge 40th question were asked. The permission was requested from the author and it was translated into Turkish. For the language validity of the MPSA-SF in this study, one language expert and six academicians from the special education field who had excellent command of English were consulted. In the direction of the experts' opinions necessary changes were made and it was translated back into English, the items on the original form and items on the adapted and back translated new form were compared and their similarities were then examined followed by necessary changes providing language equivalence.

Social validity questionnaire. In order to examine the opinions of students and teachers regarding Understand and
Solve! Strategy, a Social Validity Questionnaire was developed. It was prepared to identify the opinions of students regarding the program content and outcomes as well as the teachers' opinions about the development of the students who participated in this study. This questionnaire for the students consists of 10 items which can be rated on a 3-point Likert scale (never-always). The questionnaire for the teachers includes 10 items which can be rated on a 5-point Likert scale (Never-Rarely-Sometimes-Generally-Always).

\section{Experimental Procedures}

In this study experimental procedure was implemented in five stages as the baseline, instruction, post-instruction assessment, generalization, and follow-up. Before the experimental stages, a 12 session pilot study was conducted with a student with intellectual disabilities who had the prerequisite skills until the student acquired the problem solving skills. During the pilot study, an observer monitored the sessions and the problems recognized by the observer and the researcher were corrected and then then experimental procedure was initiated. The experimental process was implemented by the first researcher. The researcher is an expert in special education field and he has publications and presentations regarding teaching mathematics to students with intellectual disabilities.

During the experimental process, one-to-one sessions were held with each student every day of the week at the predetermined times. With each subject the sessions were conducted at the first lesson. The study lasted five months. Baseline. In the baseline, the subjects' performance on one-step addition and subtraction change problems and generalization problems was identified. Students were given a worksheet containing 10 mathematical problems and they were asked to solve these problems. In each session same type but different problems were provided to the students and at least three consecutive sessions of baseline level were conducted to identify the initial level of the performance. Generalization baseline was conducted one time for the first student, two times for the second and three times for the third student. In addition, before the instruction by MPSA-SF student's performance was identified.

Implementation of "Understand and Solve! Strategy". When the baseline data were stable, Understand and Solve! Strategy was implemented. In the study, every session was conducted every day until the instruction was over. Sessions were planned to be 30 minutes with 10 minutes break. During the instruction of Understand and Solve! Strategy the number and duration of each instruction stage conducted for each of the subjects are given in Table 3.

Post instruction assessment. Having completed the implementation, post-instruction assessment was conducted for three consecutive sessions likewise the collection of baseline data. When one student's accuracy was $90 \%$

Table 3. Number and duration of sessions implemented with each subject during Understand and Solve! Strategy instruction

\begin{tabular}{lcccccc}
\hline & \multicolumn{2}{c}{$1^{\text {st }}$ Subject } & \multicolumn{2}{c}{$2^{\text {nd }}$ Subject } & \multicolumn{2}{c}{$3^{\text {rd Subject }}$} \\
\hline Instruction Sessions & \# of Sessions & Duration & \# of Sessions & Duration & \# of Sessions & Duration \\
\hline $\begin{array}{l}\text { Developing and activating background } \\
\text { knowledge }\end{array}$ & 2 & 60 & 2 & 60 & 2 & 60 \\
\hline Discussion & 2 & 60 & 2 & 60 & 2 & 60 \\
\hline Modeling & 5 & 105 & 4 & 100 & 5 & 130 \\
\hline Supporting the strategy & 2 & 90 & 2 & 60 & 2 & 60 \\
\hline Independent Practice & 2 & 60 & 2 & 60 & 2 & 60 \\
\hline Total & 13 & 375 & 12 & 340 & 13 & 370 \\
\hline
\end{tabular}


or more at the end of the instruction and the data were stable, post-instruction assessment was terminated and baseline data were gathered from other subjects. At the end of the instruction, performance of the students was examined by MPSA-SF. Generalization post-instruction assessment was conducted likewise in the baseline as a single session following generalization instruction.

In order to examine the generalization of the students' strategy use to the classroom environment, 10 one-step change problems were given to the students and their use of the strategy then was observed.

Generalization instruction. How to solve the one-step categorization problems including addition and subtraction as well as comparison problems, and two-step change problems including with addition and/or subtraction were modeled once using Understand and Solve! Strategy.

Follow-up. Follow-up data were collected in order to examine whether students still maintained their achievements of solving change problems including a one-step addition and subtraction 3, 5, and 8 weeks after the post-instruction assessment of Understand and Solve! Strategy. Generalization follow-up data related to problems of different type and including multiple steps were collected 3, 4, and 5 weeks after.

Implementation of social validity questionnaires. Following post-intervention assessment, social validity questionnaires were filled by students and teachers.

\section{Data Collection and Scoring}

In this study five types of data were collected as the effectiveness, follow-up and generalization, data gathered from MPSA-SF, and social validity. In the following section data collection and scoring are explained.

Data collection and scoring related to effectiveness, follow-up and generalization and scoring. Assessments were conducted to identify the correctly solved problems in the baseline, post-instruction, and follow-up phases. Before starting assessments, the following statement was provided to the student "We will solve some mathematical problems" After the researcher told the student as "Are you ready to solve the problems?" and received the answer of "I am ready" the researcher put one worksheet in front of the student and he put another in front of himself and provided instruction as "Read the problems carefully and solve them" The researcher thanked the student when s/he finished the worksheet and worksheets were then removed. The researcher recorded how many problems the student answered correctly, incorrectly or s/he left blank on the problem solving record chart. The correctly solved problems were scored as 1 point. The problems with correct solutions were accepted as correct, the ones that were incorrect or left blank were accepted as incorrect. In order to examine the generalization of the strategies into the classroom, strategies that the students used solving the problems on the worksheet in their classrooms during their mathematics lessons were recorded on the Strategy Observation Form. The number of each strategy the students used for these 10 problems on the worksheet were calculated and scored on Strategy Observation Form.

Implementation of MPSA-SF and scoring. MPSA-SF was conducted face to face with the student. At the beginning, the student was provided the following statements "There are three mathematical problems here. I will read them to you. You need to solve them." And the researcher read all the problems and asked the student to listen them carefully. These problems included change, categorization, and comparison with addition or subtraction. The first prob- lem included a one-step change problem that required the outcome amount, the second included a one-step change problem that required the change amount, and the last one included a one-step change problem that required the starting amount. Later the student was told "I want you to answer the questions I will ask you, when you are ready, we can start, I will write down your answers." When the student said "I am ready" first 10 questions were verbally presented. On the first part, in order to identify the student's perception of the mathematics the questions 1-3, attitudes towards the mathematics the questions 3-7, and knowledge of mathematical problem solving strategies questions 8-10 were asked by the researcher.

On the second part, the student was provided the problems that the researcher read to her/him and with the instruction of "solve the problems" the assessment was initiated. The researcher told the student "If you have difficulty in reading or understanding the words you can ask my help. When you finish solving the problem let me know." The student was provided one problem at a time and when s/he finished all the problems s/he was handed the problems for her/him to check the problems. The student was expected to solve the problems in 10-12 minutes, if s/ he could not solve the problem the researcher then said "Ok, I will ask you other questions" and the problem was put away. Later the researcher asked the open ended questions on MPSA-SF starting from the 11th question. Answers to each question was noted under the related question. As previously indicated, on MPSA-SF there are questions to identify reading strategy (questions 11-17), interpretation (questions 18-21), visualization (questions 22-25), prediction (questions 30-33), calculation (questions 34-36), checking (questions 37-39), and to identify mathematical problem solving strategy knowledge there was the 40th question. All the assessment process was video recorded.

For mathematical perception, attitudes towards mathematics and problem solving, the first five questions were scored as 1 to 5 (bad to very good). The answers to onestep problems including change, categorization, and comparison were noted as correct-incorrect. Answers given by the students to the open-ended questions regarding problem solving strategy knowledge, use, and control (640) were analyzed. The answers were scored 0 to 5 (never $=0$, very little=1, a little $=2$, average $=3$, good=4, and very $\operatorname{good}=5)$.

Social validity data collection. Before conducting the social validity questionnaire to the students, to make students become familiarized with such questionnaires since they had not any experience with such tools, a similar questionnaire was administered with them about a subject that the students had experience. After this, social validity questionnaire was given to the student and s/he was asked to read the items and answer them one by one, s/he was assured to ask if there was anything she/he did not understand. The teachers were provided with the questionnaire and they were asked to answer the questions.

\section{Data Analysis}

Two types of graphics were used for data analysis. Problem solving performance of the students and MPSA-SF data (Montague, 1992) were shown in line graphics. The baseline data and pretest data were compared to the post-instruction data. The increase in the data having implemented the independent variable compared to the baseline level indicates the effect of the strategy. Generalization data of students' use of strategies in the classroom were also shown in line graphics. Generalization of problem solving performance to the classroom environment was shown in a bar chart. Answers to the social validity 
questionnaire were descriptively analyzed and the results were interpreted accordingly.

Procedural fidelity. Procedural fidelity was assessed at the beginning and end of the experimental process. With the first student an observer was present at the beginning of the experimental process and she observed both the assessment and intervention sessions. The observer had a master's degree in special education field. She was informed about how to use the observer fidelity forms. She was seated at a quiet place in the room where she could see the implementation and would not draw attention of the student. During this process, procedural fidelity quotient was calculated for both assessment and intervention sessions, and when the quotient was $90 \%$ or more for at least three successive sessions, the observation process was terminated. The same process was conducted at the end of the experimental process for implementation and assessment sessions as well. Both for assessment and intervention sessions, samples were selected from each student and procedural fidelity was calculated for at least $30 \%$ of the sessions. Procedural fidelity for this research study was $100 \%$ for assessment and $95.65 \%$ for the in struction (range between 95.25\% - 96\%).

Interobserver agreement. In this study, from each of the student sample sessions were chosen including all assessment sessions (baseline, post-instruction assessment, generalization, and follow-up) of problem solving variable and for $32 \%$ of the research data interobserver agreement was calculated. The observer had a master's degree in special education field. The observer was provided the student's problem solving sheets and she was asked to identify the number of correct answers related to the addition and subtraction problems. For all the subjects the interobserver agreement was 100\%.

To provide reliability of the answers given to the open-ended questions of the MPSA-SF, the researcher and an expert from the field of special education scored the answers. Interrater reliability for the first, second, and third subject was 90,92 , and 90 , respectively.

\section{Results}

Baseline, post-instruction, and follow-up data related to solving change problems including one-step addition and subtraction are given in Graphic 1.

As it can be seen in Graphic 1, the level of data path obtained at the end of the Understand and Solve! Strategy is higher than the baseline. All three subjects met the criteria of $90 \%$ at post-instruction. In addition, follow-up sessions showed that there was not any decrease in the data compared to the post-instruction.

Generalization of subjects' performance related to solving change problems including one-step addition and sub-

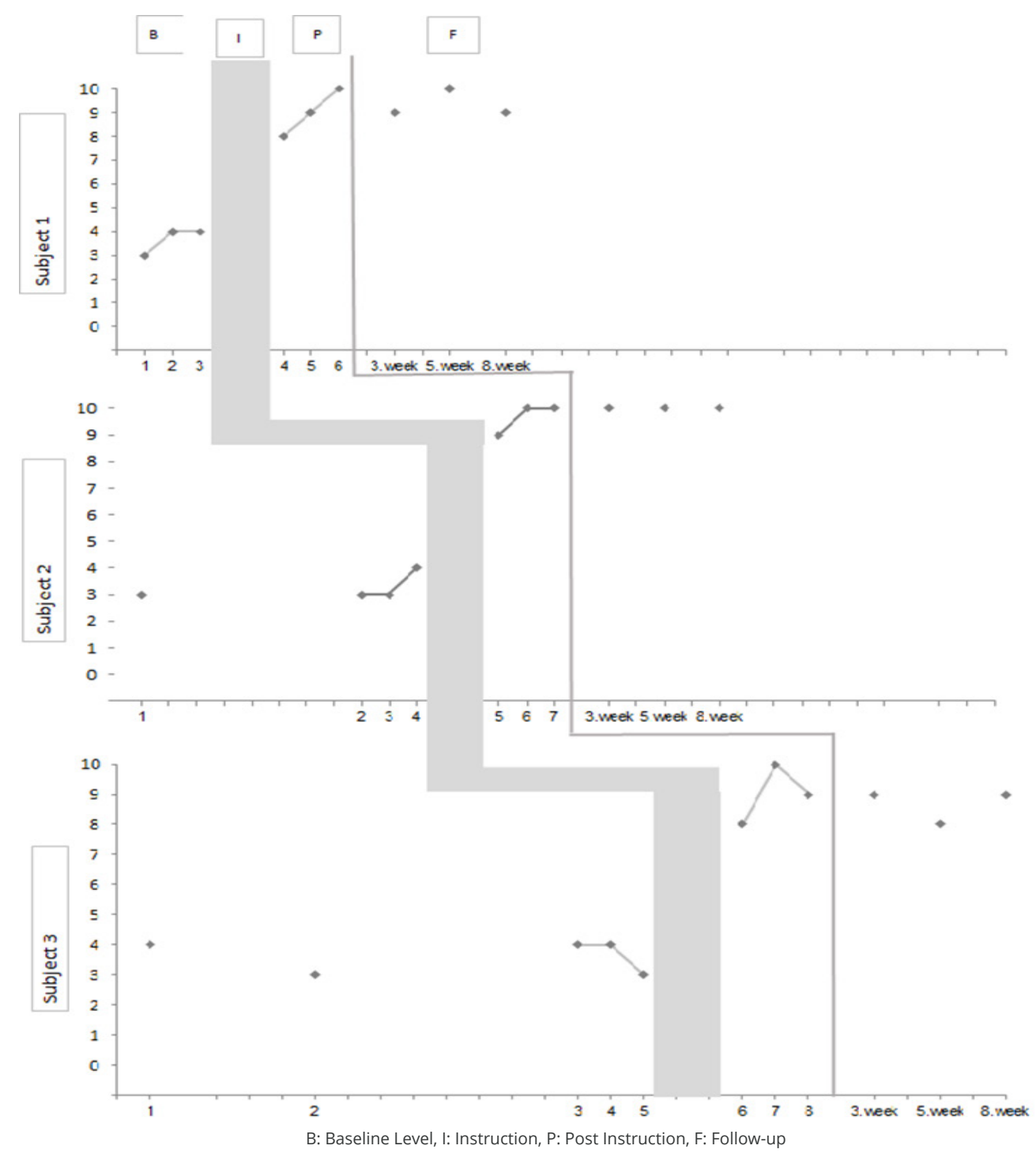

Graphic 1. Baseline, post-instruction, and follow-up results related to students' solving change problems including one-step addition and subtraction. 
traction into classroom environment regarding pre- and post-instruction are given in Graphic 2.

Subject 1

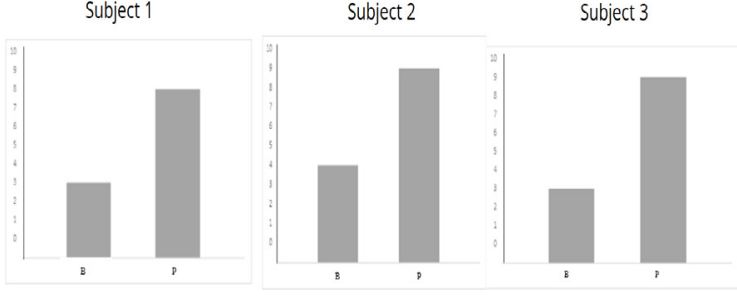

B: Baseline Level, P: Post-instruction

Graphic 2. Generalization of subjects' performance related to solving change problems including one-step addition and subtraction into classroom environment regarding pre- and post-instruction

All subjects generalized their problem solving performance to their classrooms after the Understand and Solve! Strategy instruction. During solving 10 problems the subjects exhibited "read and tell the problem" strategy 9 times on average, "underline the keywords" strategy 10 times on average, "draw the schema of the problem" strategy 9 times on average, "make a plan and solve the problem" strategy 9 times on average, and "control all steps" strategy 8 times on average. Self-instruction, which is a self-regulation strategy, was seen in 9 out of 10 problems on average, self-monitoring during the strategy steps was seen in 9 out of 10 problems on average. Generalization of subjects' solving change problems including one-step addition and subtraction are given in Graphic 3.

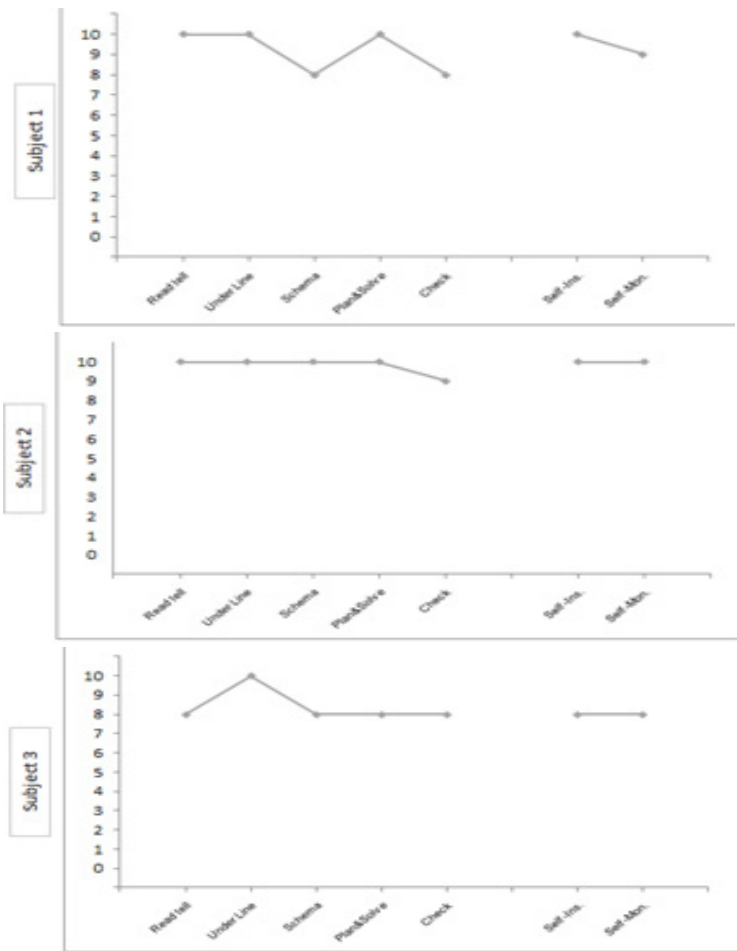

Graphic 3. Generalization of subjects' use of strategies into their classrooms

As it can be seen in Graphic 3, all three subjects generalized strategies to solve change problems including onestep addition and subtraction as well as self-regulation strategies to the classroom.

Baseline, post-instruction, and follow-up data of subjects' generalization of one-step categorization and comparison problems and two-step change problems including addition and subtraction are given in Graphic 4.

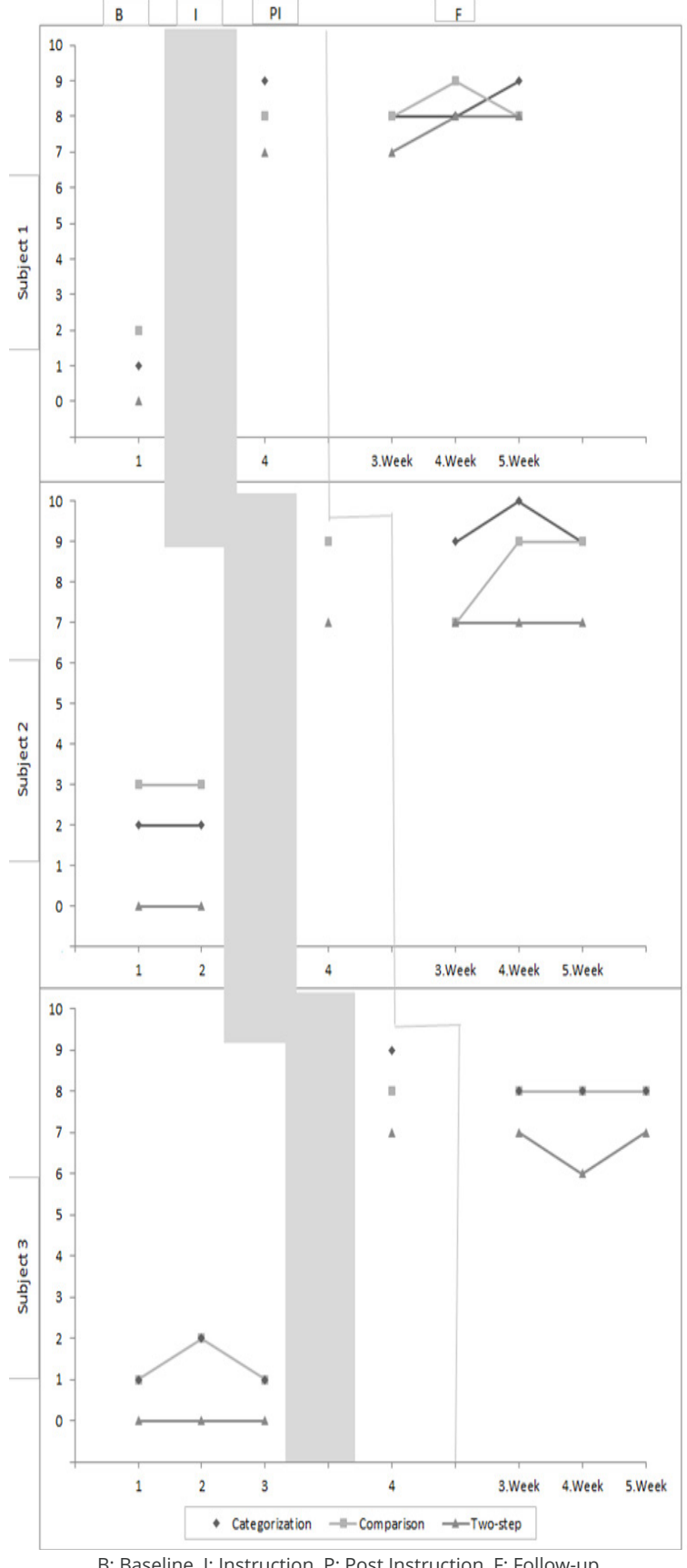

B: Baseline, I: Instruction, P: Post Instruction, F: Follow-up

Graphic 4. The number of correct answers of the subjects to one-step categorization and comparison, and two-step change problems

As it can be seen in the Graphic 4, when the baseline level and post-instruction data level were compared, it was seen that for all three subjects the difference in the level was higher than the baseline level. The subjects reached $80 \%$ to $90 \%$ accuracy in one-step categorization problems at the end of the instruction. In addition, in the subsequent follow-up sessions, the first and second subject's number of correctly solved problems did not change. Only the accuracy of the third subject decreased one point.

For comparison problems, the subjects showed $80 \%$ to 90\% accuracy. In addition, at the post-instruction their number of correctly solved problems did not change in the follow-up. For two-step change problems including addition and subtraction, the subjects had $70 \%$ accuracy at the post-instruction. Moreover, in the follow-up the 
number of correctly solved problems increased one point for the first subject and remained the same for the second and third subjects.

Subjects' pre- and post-test findings related to their perceptions about mathematics, attitudes towards mathematics and solving mathematical problems; knowledge, use, and control of problem solving strategy which were assessed by the 5 -point Likert-type MPSA-SF questions are given in Graphic 5.
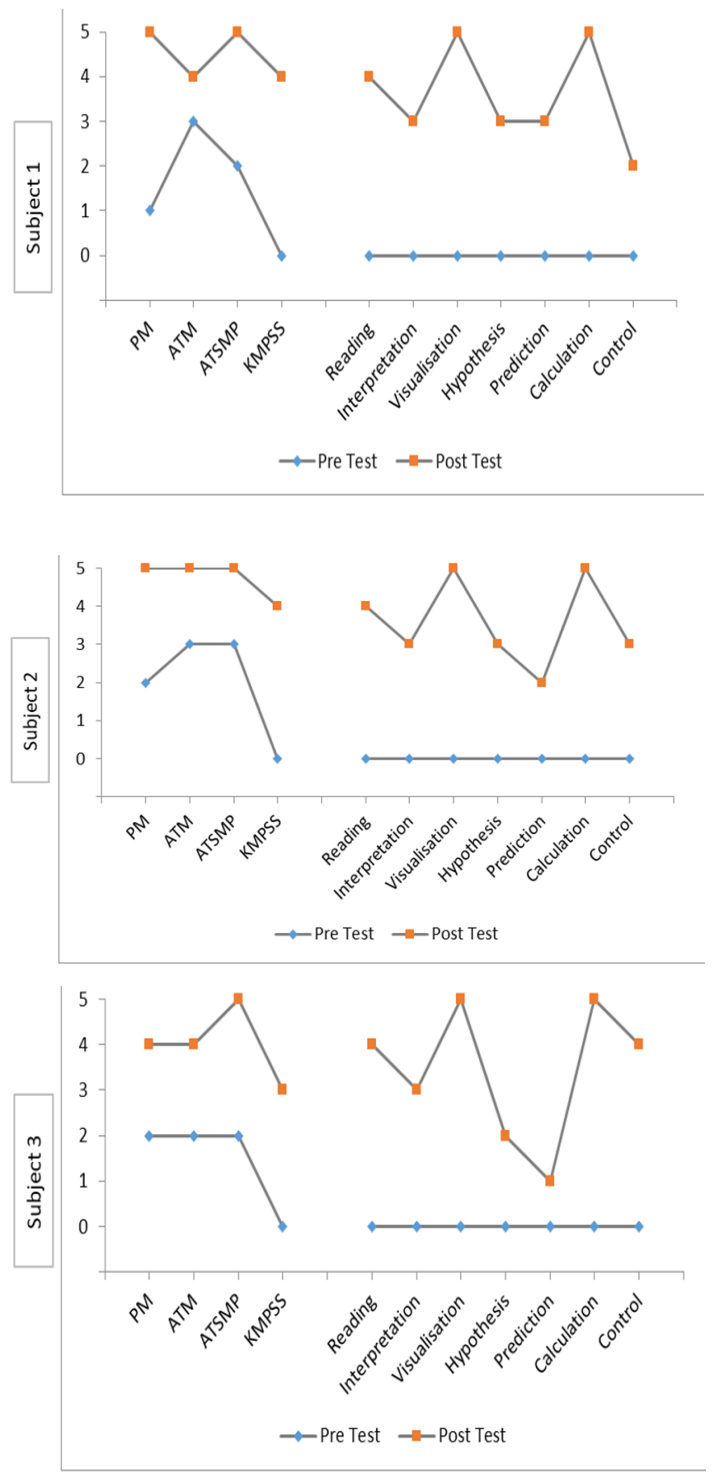

MP: Perception of Mathematics, ATM: Attitudes towards Mathematics, ATSMP: Attitudes towards Solving Mathematical Problems, KMPSS: Knowledge of Mathematical Problem Solving Strategy

Graphic 5. Subjects' data related to their perceptions about mathematics, attitudes towards mathematics and solving mathematical problems; knowledge, use, and control of problem solving strategy which were obtained by the MPSA-SF

When the subjects' pre- and post-instruction scores are compared it can be seen that their scores on all of the variables in MPSA-SF increased. Attitudes towards mathematics (1 point on average) and prediction (2 points on average) increased less than other strategies. Knowledge of solving mathematical problems strategy ( 3 points on average), visualization (5 points on average), and calculation (5 points on average) increased more.

Social Validity Results
Table 4 includes the responses of the students to the items of social validity questionnaire.

Table 4. Responses of students to the social validity questionnaire

\begin{tabular}{|c|c|c|}
\hline Items & Never Sometimes & Always \\
\hline $\begin{array}{l}\text { 1. Understand and } \\
\text { Solve! Strategy helps } \\
\text { me solve mathematical } \\
\text { problems. }\end{array}$ & & 3 \\
\hline $\begin{array}{l}\text { 2. I will use Understand } \\
\text { and Solve! Strategy in } \\
\text { Mathematics lessons } \\
\text { from now on. }\end{array}$ & & 3 \\
\hline $\begin{array}{l}\text { 3. It was easy to use } \\
\text { Understand and Solve! } \\
\text { Strategy. }\end{array}$ & & 3 \\
\hline $\begin{array}{l}\text { 4. I had fun while learn- } \\
\text { ing how to use Under- } \\
\text { stand and Solve! Strat- } \\
\text { egy. }\end{array}$ & & 3 \\
\hline $\begin{array}{l}\text { 5. I really liked the work- } \\
\text { sheets we used while } \\
\text { learning Understand } \\
\text { and Solve! Strategy. }\end{array}$ & & 3 \\
\hline $\begin{array}{l}\text { 6. Understand and } \\
\text { Solve! Strategy lessons } \\
\text { made me learn the } \\
\text { strategy easily. }\end{array}$ & & 3 \\
\hline $\begin{array}{l}\text { 7. I had so much fun } \\
\text { while using the sche- } \\
\text { mas in Understand and } \\
\text { Solve! Strategy. }\end{array}$ & & 3 \\
\hline $\begin{array}{l}\text { 8. The schemas in Un- } \\
\text { derstand and Solve! } \\
\text { Strategy help me a lot } \\
\text { in solving problems. }\end{array}$ & & 3 \\
\hline $\begin{array}{l}\text { 9.While implementing } \\
\text { Understand and Solve! } \\
\text { Strategy thinking out } \\
\text { loud helped me a lot. }\end{array}$ & & 3 \\
\hline $\begin{array}{l}\text { 10. I recommend my } \\
\text { friends Understand } \\
\text { and Solve! Strategy } \\
\text { who have difficulties in } \\
\text { solving mathematical } \\
\text { problems. }\end{array}$ & & 3 \\
\hline
\end{tabular}

According to the social validity questionnaire students' opinions related to the Understand and Solve! Strategy were positive.

In Table 5 responses of teachers to the social validity questionnaire are provided.

According to the social validity questionnaire it can be seen that the teachers' opinions about Understand and Solve! Strategy were positive.

\section{Discussion}

\section{Discussion of the effectiveness findings}

The findings of this study showed that Understand and Solve! Strategy was effective in teaching students with mild intellectual disabilities solving change problems including one-step addition and subtraction, they main- 
Table 5. Teachers' responses to the items on the social validity questionnaire

\begin{tabular}{|c|c|c|c|c|c|}
\hline Items & Never & Rarely & Sometimes & Generally & Always \\
\hline $\begin{array}{l}\text { 1. In mathematics lessons, my student engages in the lesson } \\
\text { more than s/he used to do before attending the study. }\end{array}$ & & & & 1 & 2 \\
\hline $\begin{array}{l}\text { 2. My student can correctly solve the mathematical problems I } \\
\text { hand out during the lessons. }\end{array}$ & & & & & 3 \\
\hline $\begin{array}{l}\text { 3. My student finishes the homework I give in the mathemat- } \\
\text { ics lessons. }\end{array}$ & & & & 3 & \\
\hline $\begin{array}{l}\text { 4. My student does the homework of mathematical problems } \\
\text { correctly. }\end{array}$ & & & & 3 & \\
\hline 5. My student asks for help less while solving problems. & & & & 3 & \\
\hline $\begin{array}{l}\text { 6. My student makes drawings while solving the problems to } \\
\text { visualize the problem. }\end{array}$ & & & & 1 & 2 \\
\hline
\end{tabular}

tained their skills and generalized their skills to different problem types, two-step change problems, and to classroom environment. These results are consistent with the findings of the studies conducted using Modified Solve It! Strategy students with learning disabilities (Daniel, 2003; Krawec, Huang, Montague, Kressler, \& Alba, 2012; Montague, 1992) and intellectual disabilities (Chunk \& Tam, 2005). In this study, different than Modified Solve It! Strategy, Understand and Solve! Strategy was implemented. Even though Understand and Solve! Strategy is different in terms of presentation in several steps than Modified Solve It! Strategy, these strategies have common strategy steps. In their study, Chung and Tam (2005) found that Modified Solve It! Strategy was effective on the performance of problem solving of students with intellectual disabilities and maintaining this performance 2 weeks after the instruction. They linked this to modifying Solve It! Strategy as well as the fact that students with intellectual disabilities learned the cognitive and metacognitive strategies. In the current study, the observations conducted in the classrooms showed that students were able to implement all the strategies. At the end of the instruction, the students carefully read the problem, underlined the keywords, expressed the problem in their own words, drew an appropriate schema, planned the problem solution, predicted what would be the outcome, performed the calculation, and checked the outcome. In this regard, it might be suggested that the reason why the Understand and Solve! Strategy was effective was that the characteristics of the presentation of the strategy were adapted to fit the characteristics of the students with intellectual disabilities as well as the students learned the strategy steps. In addition, as a common characteristic of cognitive strategy instruction, Understand and Solve! Strategy implemented the following steps respectively: read and tell, underline the keywords, draw a schema of the problem, make a plan and solve the problem, control it. Implementing these steps in a holistic way might have played a role in using cognitive strategies and processes which take place in students' problem solving process, thus yielding accurately solving the problem (Montague, 1992). It is thought that presenting Understand and Solve! Strategy with self-regulation approach might have contributed to the positive results on effectiveness, maintenance, and generalization of students' skills. Understand and Solve! Strategy has the components of "self-instruction" and "self-monitoring through strategy steps" which are metacognitive strategies. Individuals need self-talk to manage, organize, and construct their cognitive functions to help prepare appropriate action plans and better understand the problems (Case et al., 1992). With self-instruction this self-talk is improved. This self-talk is not used to communicate with others, rather it is used to manage, organize, and con- struct cognitive functions (Case et al., 1992). Self-instruction statements ensure the understanding of the students about how to implement the strategy, develop effective and efficient strategies, and use these strategies in problem solving to monitor and to maneuver (Case et al., 1992; Cassel \& Reid, 1996). In the current study, the students started using statements while solving problems to identify the necessary strategies, remind oneself which strategy or skill to use in a certain step, self-reinforce, and to control the steps. With these observations in mind it could be suggested that students developed self-talk during the problem solving. Therefore, self-instruction is thought to have a great role in obtaining effective results related to problem solving. In the current study, self-monitoring, which is one of the metacognitive strategies for self-regulation, was utilized. Self-monitoring helps students follow the strategy steps accurately and completely and follow the certain tasks at specific steps while solving problems, thus yielding self-control (Montague, 2007). In this study, self-monitoring was used during the implementation of respective strategy steps. Self-monitoring might have helped the students easily monitor whether they implemented the strategy steps used in the problem solving or not and learn the strategy steps as well as it might have helped to contribute to the self-control, and self-assessment.

Other characteristics of Understand and Solve! Strategy include the following: arrangement of the strategy instruction according to the SRSD teaching steps, setting a criterion for transition to the next step in instruction, internalization of the self-instruction for the students, and including procedural facilatators used in cognitive strategy teaching to make students learn the strategy. As indicated in the literature, during the stages of "Modeling, Guided Practice, and Independent Practice" the teacher needs to model the strategy steps and gradually fade the guidance and require the student independently implement the strategy and thus setting criterion for these stages might contribute to the independence in implementation (Case et al., 1992; Cassel \& Reid, 1006; Graham \& Harris, 2003). The accuracy of the students' answers to the problems during the teaching of Understand and Solve! Strategy was in direct proportion to the accurately use of strategy steps. When the subjects implemented the strategy steps accurately and fully their performance increased more rapidly. When a subject forgot one or more of the strategy steps they could not solve the problem correctly. It is stated in the literature that the strategy teaching must be explicit (Case et al., 1992; Cassel \& Reid, 1996; Doğanay-Bilgi, 2009; Graham \& Harris, 2003, pp.323-324; Güzel-Özmen, 2006; Güzel-Özmen, 2011; Krawec et al., 2012; Montague \& Dietz, 2009; Swanson et al., 2014). It is thought that pre- 
senting Understand and Solve! Strategy according to the SRSD stages might have led the students with mild intellectual disabilities implement these steps as well as learn, maintain, and generalize the strategy.

The results of the studies in which cognitive strategy was instructed showed that student with various disabilities generalized their problem solving skills to different types of problems and different settings (Case et al., 1992; Chung \& Tam, 2005; Cote et al., 2010; Daniel, 2003; Huffman, Fletcher, Grupe, \& Bray, 2004; Iseman \& Naglieri, 2011; Keogh, Whitman, \& Maxwell, 1988; Maccini \& Gagnon, 2001; Maccini \& Hugles, 2000; Mancl, 2011; Montague \& Dietz, 2009; Montague, 1992; Montague, 2008; Naglieri \& Das, 1997; Naglieri \& Gottling, 1995; Naglieri \& Johnson, 2000; Rosenzweig et al., 2011; Van Luit \& Van der Aalsvoort, 1985). In the current study, Understand and Solve! Strategy teaching also increased the students generalization performance. In their study of examining the effectiveness of Understand and Solve! Strategy to students with intellectual disabilities Cassel and Reid (1996) investigated the generalization of skills to classroom environment and they suggested teaching generalization to students with intellectual disabilities. In the current study, the researcher modeled only once to show the students how to use the strategy in generalization problems and for students to learn the problem structure. With only one session of generalization instruction to show how to implement Understand and Solve! Strategy with different type of problems was sufficient for the subjects to generalize the strategy. The reason for that could be that during the instruction of Understand and Solve! Strategy the implementer does not only teach solving change problems. In the foundation of teaching cognitive strategies lies the teaching the strategy rather than the targeted skills. When the students learned the strategy, they became aware of the skill structure thus they were able to generalize the strategy to different types of problems even to problems that were more difficult such as the two-step problems. In the follow-up and generalization performance of the subjects, both increased metacognitive experiences and more internalized cognitive strategies might have played a role. A common characteristic of cognitive strategy teaching is that the strategy steps are implemented by thinking out loud and interactive dialogs take place during the implementation, thus leading the student internalize the strategy (Özmen, 2017). During this study, the students were observed to be extensively using thinking out loud in the guided practice, independent practice, and post-instruction assessment process that they were not observed to be used during the baseline. This kind of thinking process might show that they started to internalize the strategy. In addition, the subjects indicated that they really liked to use the strategy as they used self-regulation statements such as "I know what to do to solve the problem, the problem solving has become fun, because I already solved such problems before." These statements show that their metacognitive experiences increased. When the metacognitive experiences increase strategy generalization performance also increases (Efklides, 2001; 2006; Efklides \& Petkaki, 2005).

\section{Discussion of MPSA-SF Findings}

At the end of the intervention, students' scores on MPSA-SF increased and students' knowledge, use, and control of solving mathematical problems improved. These findings are consistent with the findings of research studies implementing Solve It! Strategy (Montague, 2008; 2007; 1992).

When the pre-test and post-test scores were compared, it was seen that the smallest change was for attitudes towards mathematics, but the greatest change was for the knowledge of strategy for solving the mathematical problems. The reason for the less change in the attitudes towards mathematics might be that prior to the study the students' problem solving strategy knowledge was insufficient or they were using insufficient strategies. Accordingly, students did not get any points from this measure before the instruction. For the strategy knowledge; self-instruction and self-questioning are needed and for strategy control self-monitoring strategies need to be implemented (Montague, 2008; 2007; 1992). There was an increase in the post-test scores of strategy knowledge of the students with mild intellectual disabilities that might have been due to self-instruction, self-monitoring, and presentation of strategy steps during the modeling, guided practice, and independent practice stages of Understand and Solve! Strategy. However, this increase is less than the findings reported in the previous research studies (Daniel, 2003; Krawec et al., 2012; Montague, 1992; Sweeney, 2010). This difference might be due to the fact that MPSA-SF's questions about the strategy knowledge and control do not overlap with the strategy knowledge given in Understand and Solve! Strategy. In the Understand and Solve! Strategy the prediction step did not take place. Therefore, the scores of students about prediction and control were low. Mathematical problem solving strategy use and control. When the students' use and control of mathematical problem solving strategy were examined it was seen that there were improvements in all of the strategies, however, the highest improvements were in visualization and calculation (5 points), and the lowest improvements were in hypothesis development and prediction (1 point to 3 points). There are previous studies in which findings showed that the increase in the post-test scores of mathematical problem solving strategy use and control compared to the pre-test scores were higher than the findings in this study (Daniel, 2003; Krawec et al., 2012; Mesler, 2004; Montague, 1992; Montague \& Dietz, 2009; Whitby, 2009). In those studies, Solve It! Strategy was used. Since the MPSA-SF overlaps with the strategy steps included in Solve It! Strategy, it might provide an explanation for the reason why the increase in the scores in the previous studies were higher. Similar to the findings of the current study, results in terms of the strategy use and control, in studies in which Solve It! Strategy was modified, the scores of the students were higher than the studies in which this strategy was not modified (Chung \& Tam, 2005; Daniel, 2003; Krawec et al., 2012; Mesler, 2004; Montague, 1992). Therefore, the difference between the pre- and post-test results might be due to adaptation in the strategy and that the assessment tool did not overlap with the strategy steps.

Perceptions about Mathematical Performance. At the pre-test before the instruction students' scores related to the perceptions about their mathematical performance were at least 1 to at most 2 out of 5 , whereas at the posttest after the instruction their scores were at least 4 to at most 5 out of 5 . These findings related to the perceptions about mathematical performance are consistent with the findings of previous studies in which MSPA-SF was implemented during strategy instruction. At the end of the instruction, scores related to the perceptions of mathematical performance were higher for students with learning disabilities (Daniel, 2003; Krawec et al., 2012; Montague, 1992; Sweeney, 2010), learning disabilities and intellectual disabilities (Montague \& Dietz, 2009), Autism and Asperger's syndrome (Whitby, 2009) as well as Spina Bfida (Mesler, 2004). These results show that teaching cognitive strategies in problem solving might improve the perceptions of students about the mathematical performance. Moreover, self-instruction, self-questioning, self-monitoring, which are metacognitive elements included in the cognitive strategy teaching, might play a role in perceptions about the mathematical performance (Montague \& Applegate, 2000). Schraw (1998) indicated that optimizing 
the sources, better implementing the known strategies, and recognizing the problems might increase the performance. Case et al. (1992) also emphasized that when students used self-regulation strategies this positively affected the academic success. Self-instruction, which was one of the components of the Understand and Solve! Strategy used in the current study, might have role in changing perception related to mathematical performance.

Attitudes towards Mathematics. When the findings of the subjects of this study regarding attitudes towards mathematics were examined, it was seen that their scores related to their attitudes were at least 2 and at most 3 out of 5 on pre-test, whereas their scores on post-test were at least 4 and at most 5 . These findings might show that the Understand and Solve!' Strategy was effective in positively changing attitudes towards solving mathematical problems of students with mild intellectual disabilities. There are studies in the literature that examined the relationship between the number of accurately solved problems plus strategy performance and attitude of students with learning disabilities, intellectual disabilities, and autism (Daniel, 2003; Krawec et al., 2012; Mesler, 2004; Montague, 1992; Montague \& Dietz, 2009; Sweeney, 2010; Whitby, 2009) as well as the effects of the different type of instructional strategies on attitudes towards mathematics and solving mathematical problems (Daniel, 2003; Krawec et al., 2012; Mesler, 2004; Montague, 1992; Montague \& Dietz, 2009; Sweeney, 2010; Whitby, 2009). These study results show that there is a positive relationship between the increase in the number of problems solved plus strategy experience and attitudes and different type of instructional strategies might positively affect attitudes towards mathematics and mathematical problem solving. With the implementation of Understand and Solve! Strategy, the subjects learned the problem solving process and the cognitive and metacognitive strategies necessary for problem solving and they reached the accurate results in problem solving using these strategies yielding metacognitive experiences might contribute to the development of positive attitudes in students.

Knowledge of mathematical problem solving strategies. The scores related to the knowledge of students regarding mathematical problem solving strategies was 0 out of 5 points on pre-test. After the instruction their scores were at least 3 and at most 4 . This finding shows that Understanding and Solve! Strategy was effective in increasing mathematical problem solving strategy knowledge of students with intellectual disabilities. Implementation of Understand and Solve! Strategy based on SRSD stages and the criterion identified for the transition from one strategy stage to other might have led to these results. These results are similar to the results of studies in which strategy teaching was implemented with students with various disabilities using MPSA-SF (Daniel, 2003; Krawec et al., 2012; Mesler, 2004; Montague, 1992; Sweeney, 2010; Montague \& Dietz, 2009; Whitby, 2009). In this study as well, similar results were obtained with students with intellectual disabilities. In this regard, the results of the study show that cognitive strategy teaching was effective on not only the skill to be taught but also the knowledge of mathematical problem solving strategy. As a consequence, the perception of the students regarding their performance, their attitudes, and strategy knowledge improved when compared to the pre-instruction.

Social validity. In this study, the results of the data gathered from the subjects and teachers showed that the opinions about the Understand and Solve! Strategy were positive. These results show that strategy teaching is positive in terms of social validity.
The limited number of studies in the literature and the results of these studies show that strategy instruction when modified for the students with intellectual disabilities is effective in making them achieve problem solving skills (Chung \& Tam, 2005). There are a few number of studies in which students with intellectual disabilities were provided with strategy instruction in academic skills. In some of these studies, strategies were modified (Chung \& Tam, 2005; Doğanay-Bilgi, 2009; Güzel-Özmen, 2006; GülerBülbül, 2016) in some other studies strategies which were effective for students with learning disabilities were implemented likewise (Alfassi, Weiss, \& Lifshitz, 2009; Cote et al., 2010; Konrad, Trela, \& Test, 2006; Lundberg \& Reichenberg, 2013). In this regard, effectiveness of the strategies implemented in the same way with students with learning disabilities and modified strategies should be tested on students with mild intellectual disabilities. Studies like that would serve to identify effective instruction for students with mild intellectual disabilities to achieve academic skills.

\section{Refences}

Alfassi, M., Weiss, I. \& Lifshitz, H. (2009). The efficacy of reciprocal teaching in fostering the reading literacy of students with intellectual disabilities. European Journal of Special Needs Education, 24(3), 291-305.

Case, L. P., Harris, K. R. \& Graham, s. (1992). Improving the mathematical problem-solving skills of students with learning disabilities: Self-regulated strategy development. The Journal of Special Education, 26, $1-19$.

Cassel, J. \& Reid, R. (1996). Use of a self-regulated strategy intervention to improve word problem solving skills of students with mild disabilities. Journal of Behavioral Education, 6,153-172.

Chung K. H. \& Tam, Y. H. (2005) Effects of cognitive-based instruction on mathematical problem solving by learners with mild intellectual disabilities. Journal of intellectual and Developmental Disability, 30(4) 207-216.

Cote, D., Pierce T., Higgins K., Miller S., Tandy R. \& Sparks S. (2010). Increasing skill performances of problem solving in students with intellectual disabilities. Education and Training in Autism and Developmental Disabilities, 45(4), 512-524

Daniel, G. E. (2003). Effects of cognitive strategy instruction on the mathematical problem solving of middle school students with learning disabilities. PhD Thesis, Ohio State University, Columbus.

Das, J. P., Naglieri, J. A. \& Kirby, J. R. (1994). Assessment of cognitive processes: The PASS theory of intelligence. Boston: Allyn \& Bacon.

Doğanay-Bilgi A., (2009). Zihinsel yetersizliği olan öğrencilerin bilgi veren metinleri anlamalarında uyarlanmış çok ögeli bilişsel strateji öğretiminin etkililiği [he effectiveness of modified multi-component cognitive strategy instruction in comprehension of expository texts students with mental retardation], Gazi Unviersity, Institute of Educational Sciences, Ankara, Turkey.

Efklides, A. (2001). Metacognitive experiences in problem solving: Metacognition, motivation and selfregulation. In A. Efklides, J. Kuhl, \& R. M. Sorrentino (Eds.), Trends and prospects in motivation research (pp. 297-323). Dordrecht, The Netherlands: Kluwer 
tacognitive experiences tell us about the learning process? Educational Research Review, 1, 3-14.

Efklides, A. \& Petkaki, C. (2005). Effects of mood on students' metacognitive experiences. Learning and Instruction, 15, 415-431.

Efklides, A., (2009). The role of metacognitive experiences in the learning process. Psicothema, 21(1) 76-82

Efklides, A., (2011). Interactions of Metacognition with motivation and affect in self-regulated learning: The masrl model. Educational Psychologist, 46(1), 6-25

Englert, C. S., Raphael, T. E. \& Anderson, L. M. (1992). Socially mediated instruction: Improving students' knowledge and talk about writing. The Elementary School Journal, 92, 411-449.

Geary, D. C. (1994). Children's mathematical development. Research and practical applications. Washington, DC: American Psychological Association.

Geary, D. C., Brown, S. C. \& Samaranayake, V. A. (1991). Cognitive addition: A short longitudinal study of strategy choice and speed of processing differences in normal and mathematically disabled children. Developmental Psychology, 27, 787-797.

Goldman, S.R. (1989). Strategy instruction in mathematics. Learning Disabilities Quarterly, 12, ss.43-55.

Graham, s. \& Harris, K. R. (2003). Students with learning disabilities and the process of writing: A metaanalysis of SRSD studies. In L. H. Swanson. K. Harris, \& S. Graham (Eds.), Handbook of learning disabilities (pp. 323-344). New York: Guilford.

Güler-Bülbül, Ö. (2016). Zihinsel yetersizlikten etkilenmiş öğrencilerin ve yazmada düşük performans gösteren akranlarının öykü yazma becerilerinde 'seç + düzenle + yaz ve oku - düzelt + paylaş - düzelt' stratejisinin etkililiği [Effectiveness of 'pick + organize + write and read - edit + share - edit' strategy on story writing of children with intellectual disability and their peers underperforming in writing]. Doctoral Dissertation, Gazi Institute of Education, Ankara, Turkey.

Güzel-Özmen, R. (2006). The effectiveness of modified cognitive strategy instruction in writing on mildly mentally retarded Turkish students. Exceptional Children, 72(3), 281-297.

Güzel-Özmen, R. (2011). Evaluating the effectiveness of combined reading interventions on improving oral reading fluency of students with reading difficulties. Electronic Journal of Research in Educational Psychology, 93, 1063-1086.

Harris, K. R. \& Graham, S. (1996). Making the Writing Process Work: Strategies for composition and self-regulation. Cambridge, MA: Brookline.

Horner, R. H., Carr, E. G, Halle, J., McGee, G., Odom, s. \& Wolery, M. (2005). The use of single-subject research to identify evidence-based practice in special education. Exceptional Children, 71, 165179.

House, A. W., House, B. G. \& Campbell, M. B. (1981). Measures of interobserver agreement: Calculation formula and distribution effect. Journal of Behavioral Assessment, 3, 37-57.
Huffman, L. F., Fletcher, K. L., Grupe, L. A. \& Bray, N. W. (2004). Similarities and differences in early addition strategies in children with and without mental retardation. Education and Training in Developmental Disabilities, 39, 317-325.

Iseman J. S. \& Naglieri J. A. (2011). A cognitive strategy instruction to improve math calculation for children with ADHD and LD: A randomized controlled study. Journal of Learning Disabilities 44(2), 184-195

Jitendra A., George M.P., Sood S. \& Price K. (2010). Schemabased instruction: Facilitating mathematical word problem solving for students with emotional and behavioral disorders. Preventing School Failure, 54(3), 145-151.

Jitendra, A. K. (2002). Teaching student's math problemsolving through graphic representations. Teaching Exceptional Children, 34(4), 34-38.

Jitendra, A. K. \& Hoff, K. (1996). The effects of schemabased instruction on the mathematical word problem solving performance of students with learning disabilities. Journal of Learning Disabilities, 29, 422- 431.

Jitendra, A. K., Star, J.R., Rodriguez, M., Lindell, M. \& Someki, F. (2011). Improving students' proportional thinking using schema-based instruction. Learning and Instruction, 21, 731-745.

Karabulut, A., Yıkmış, A., Özak, H. ve Karabulut, H. (2015). Şemaya dayalı problem çözme stratejisinin zihinsel yetersizliği olan öğrencilerin problem çözme performanslarına etkisi [The effect of schema based problem solving strategy on problem solving performance of students with intellectual disabilities]. Abant Izzet Baysal Üniversitesi Ĕgitim Fakültesi Dergisi, 15, 243-258.

Keogh, D. A., Whitman, T. L. \& Maxwell, S. E. (1988). Selfinstruction versus external instruction: Individual differences and training effectiveness. Cognitive Therapy and Research, 12, 591-610.

Krawec, J, Huang, J. Montague M., Kressler B. \& Alba A. M., (2012). The effects of cognitive strategy instruction on knowledge of math problem-solving processes of middle school students with learning disabilities. Learning Disability Quarterly, 36(2), 80 -92

Krawec, J. (2014). Problem representation and mathematical problem solving of students of varying math ability. Journal of Learning Disability 47(2), 103-115.

Lundberg, I. \& Reichenberg, M. (2013). Developing reading comprehension among students with mild intellectual disabilities: An intervention study. Scandinavian Journal of Educational Research, 57(1), 89-100.

Maccini, P. \& Gagnon, J. (2001). Preparing students with disabilities for algebra. Teaching Exceptional Children, 34(1), 8-15.

Maccini, P. \& Hughes, C. A. (2000). Effects of a problem solving strategy on the introductory algebra performance of secondary students with learning disabilities. Learning Disabilities Research\& Practice, $15,10-21$. 
Mancl, Dustin B. (2011). Investigating the effects of a combined problem-solving strategy for students with learning difficulties in mathematics. Php Thesis, University of Nevada, Las Vegas.

Marshall, S. P. (1995). Schemas in problem solving. New York: Cambridge University Press.

Mesler, J. (2004). The effects of cognitive strategy instruction on the mathematical problem solving of students with spina bifida. Php Thesis, University of Miami, Coral Gables, Florida.

Milford, T. \& Harrison, G. L. (2010). Using the PLEASE Strategy with a Struggling Middle School Writer with a Disability, Intervention in School and Clinic, 45(5), 326-332.

Montague M., Enders C. \& Dietz, S. (2011) Effects of cognitive strategy instruction on math problem solving of middle school students with learning disabilities. Learning Disability Quarterly, 34(4), 262 -272 .

Montague, M. (1992). The effects of cognitive and metacognitive strategy instruction on mathematical problem solving of middle school students with learning disabilities. Journal of Learning Disabilities, 25, 230-248.

Montague, M. (1997). Cognitive strategy instruction in mathematics for students with learning disabilities. Journal of Learning Disabilities, 30, 164-177.

Montague, M. (2000). Solve It! Strategy instruction to improve mathematical problem solving. Learning disabilities. Research and Practice, 15(2), 110-116.

Montague, M. (2007). Self-regulation and mathematics instruction. Learning Disabilities Research and Practice 22, 75-83.

Montague, M. (2008). Self-regulation strategies to improve mathematical problem solving for students with learning disabilities. Learning Disability Quarterly, 31, 37-44.

Montague, M. \& Applegate, B. (1993). Mathematical problem solving characteristics of middle school students with learning disabilities. Journal of Special Education, 27, 175-201.

Montague, M. \& Applegate, B. (2000). Middle school student's perceptions, persistence, and performance in mathematical problem solving. Learning Disability Quarterly, 23, 215-227.

Montague, M. \& Bos, C. (1986). The effect of cognitive strategy training on verbal math problem solving performance of learning disabled adolescents. Journal of Learning Disabilities, 19, 26-33.

Montague, M. \& Dietz, S. (2009). Evaluating the evidence base for cognitive strategy instruction and mathematical problem solving. Exceptional Children, 75(3), 285-302.

Naglieri, J. A. \& Gottling, S. H. (1995). A study of planning and mathematics instruction for students with learning disabilities. Psychological Reports, 76, 1343-1354.

Naglieri, J. A. \& Johnson, D. (2000). Effectiveness of a cognitive strategy intervention in improving arithmetic computation based on the PASS theory. Journal of Learning Disabilities, 33, 591-597.
National Council of Teachers of Mathematics. (1989). Curriculum and evaluation standards for school mathematics. Reston, VA: Author.

National Council of Teachers of Mathematics. (2000). Principles and standards for school mathematics. Reston, VA: Author.

Özsoy, G., \& Ataman, A. (2009). The effect of metacognitive strategy training on problem solving achievement. International Electronic Journal of Elementary Education, 1(2), 67-82.

Özsoy, G., Kuruyer, H. G., \& Çakıroğlu, A. (2015). Evaluation of Students' Mathematical Problem Solving Skills in Relation to Their Reading Levels. International Electronic Journal of Elementary Education, 8(1), 581600.

Reid, R. \& Lienemann, T.O. (2006).Self-regulated strategy development for students with learning disabilities, Teacher Education and Special Education,29(1), 3-11.

Rivera, D. P. (1997). Mathematics education and students with learning disabilities: introduction to the special series. Journal of Learning Disabilities, 30, 2-19.

Rosenzweig C., Krawec, J. \& Montague, M. (2011). Metacognitive strategy use of eighth-grade students with and without learning disabilities during mathematical problem solving: A think-aloud analysis. Journal of Learning Disabilities, 44(6), 508-520

Schraw, G. (1998). Promoting General Metacognitive Awareness. Instructional Science, 26, 113-125.

Swanson H. L., Lussier C. \& Orosco M. (2013) Effects of Cognitive Strategy Interventions and Cognitive Moderators on Word Problem Solving in Children at Risk for Problem Solving Difficulties Learning Disabilities. Research \& Practice, 28(4), 170-183

Swanson, H. L. Orosco M. J. \& Lussier C. M. (2014). The effects of mathematics strategy instruction for children with serious problem-solving difficulties. Exceptional Children 80 (2) 149-168.

Sweeney, C. M. (2010). The Metacognitive Functioning of Middle school students with and without learning disabilities during mathematical problem solving. Php Thesis University of Miami, Coral Gables, Florida.

Van Luit, J. E. H. \& Van der Aalsvoort, G. M. (1985). Learning subtraction in a special school: A self-instructional training strategy for educable mentally retarded children with arithmetic deficits. Instructional Science, 14,179-189

Whitby P. J. S. (2009) The effects of a modified learning strategy on the multiple step mathematical word problem solving ability of middle school students with high-functioning autism or Asperger's syndrome Php Thesis. University of Central Florida Orlando, Florida. 